\title{
24-Hour Sleep Duration in Early Gestation is Associated with Increased Markers of Inflammation Among Women with a History of Preeclampsia
}

\author{
Michele L Okun ${ }^{1,2, *}$, James M Roberts ${ }^{2,3,4,5}$, Amy Begley ${ }^{1}$, Janet Catov ${ }^{3,4}$ and Thelma E Patrick ${ }^{6}$ \\ ${ }^{1}$ Department of Psychiatry, ${ }^{2}$ Magee-Womens Research Institute, ${ }^{3}$ Obstetrics Gynecology and Reproductive Sciences, \\ ${ }^{4}$ Epidemiology and ${ }^{5}$ Clinical and Translational Science Institute, University of Pittsburgh School of Medicine and ${ }^{6}$ The \\ Ohio State University College of Nursing, USA
}

\begin{abstract}
Background: Sleep duration, both short and long, is recognized as a potential contributor to adverse health conditions. This study evaluated whether long sleep duration in early gestation (15 weeks) was associated with increased circulating concentrations of inflammatory cytokines across pregnancy.

Methods: Self-reported 24-hour sleep duration and blood samples were obtained concurrently at 15, 24 and 36 weeks gestation in 85 pregnant women with a history of preeclampsia. Plasma samples were assayed for the inflammatory cytokines IL-2, -6, -8, IFN $\gamma$, TNF $\alpha$, GM-CSF and anti-inflammatory cytokines IL-4, -5, and -10 using Luminex technology. A ratio of pro-to-anti-inflammatory cytokines was calculated using multiples of the median (MOMs) for each relevant cytokine type to normalize the data for comparison. Data were analyzed using repeated measures mixed models.

Results: Women with long sleep ( $\geq 9$ hours) at 15 weeks gestation had higher IL-6 concentrations throughout gestation than women who were regular sleepers $(\mathrm{p}=.003)$. No other cytokine or the ratio of pro-to-inflammatory cytokines differed between groups. No interactions of group by time were significant.

Conclusions: The tendency to sleep for more than 9 hours in early pregnancy may contribute to increased low-grade inflammation as evidenced by higher circulating concentrations of IL-6. This may initiate or augment pre-existing pathophysiology associated with adverse pregnancy outcomes. While, our data are preliminary, they direct further investigation to determine whether this association increases risk for adverse pregnancy outcomes.
\end{abstract}

Keywords: Sleep duration, pregnancy, cytokine, inflammation, preeclampsia.

\section{INTRODUCTION}

Sleep duration, both short and long, is recognized as a potential contributor to adverse health conditions including cardiovascular disease $[1,2]$ and Type 2 diabetes [3]. Despite the mutual recognition, most investigations have more often considered how short sleep duration contributes to adverse health outcomes [1, 4-6]. This emphasis is likely due to the long-term and continuing decline in habitual sleep duration from 8 to $6 \frac{1}{2}$ hours per night, particularly among women [7]. Long sleep duration, on the other hand, is most often assessed in association with increased psychopathologic symptoms and increased risk for mortality [8-10]. Recently some investigations have reported that long sleep ( $\geq 9$ hours), in addition to short sleep duration, is indeed a risk factor for metabolic syndrome [11], Type 2 diabetes [12] and cardiovascular disease [3, 13]. These findings suggest that long sleep while often overlooked, is an important correlate to consider when evaluating sleep and health [8].

*Address correspondence to this author at the Western Psychiatric Institute and Clinic, 3811 O'Hara St., Pittsburgh, PA 15213, USA; Tel: 412 586-9434; Fax: 412 246-5300; E-mail: okunml@upmc.edu
Pregnant women report a host of sleep disturbances beginning in the first trimester [14-18]. Not surprisingly, many women indicate they require or obtain longer sleep duration than before they became pregnant. To date, the emphasis between pregnancy-related sleep disturbances and health has been on sleep disordered breathing (SDB) during pregnancy [19-21]. While the consequences of SDB are emerging as critically important to maternal and fetal outcomes [22-25], there is sufficient evidence that other facets of sleep, including sleep duration (either short or long) are also important to adverse pregnancy outcomes [5, 26, 27]. Among the small literature, two have focused on gestational diabetes with one considering the relationship between long sleep and gestational hypertension $(\mathrm{GH})$ as well as preeclampsia [26]. GH is an important risk factor to understand as women who have GH in early pregnancy often go on to develop preeclampsia or have a small for gestational age baby. Both of these conditions are further associated with a woman delivering preterm, which also contributes to fetal morbidity $[28,29]$. It is clear that additional information is needed to understand the effects of long sleep on pregnancy outcomes.

Among the myriad physiological changes that take place during pregnancy, inflammation (increases in proinflammatory cytokine expression) is important to consider. 
It is not only an identified pathway linking disturbed sleep and poor outcomes [30, 31], but imbalances of the cytokine milieu both in the maternal periphery as well as the fetoplacental unit may be associated with the pathogenesis of adverse pregnancy outcomes [32-34]. Emerging evidence suggests that poor sleep quality and upper airway resistance during pregnancy are associated with higher levels of inflammatory markers $[16,35,36]$. In vitro studies indicate that inflammatory cytokines can inhibit invasion of human trophoblasts [37-39]. Furthermore, women with adverse pregnancy outcomes, such as preeclampsia, have increased concentrations of inflammatory cytokines compared to women with normal pregnancies $[40,41]$ however, the majority of the evidence is retrospective.

Given the indication that disturbed sleep contributes to inflammation, and the association between inflammation and adverse pregnancy outcomes, we evaluated whether long sleep duration across 24-hours in early gestation was associated with subsequent inflammation known to contribute to adverse pregnancy outcomes. To begin this preliminary look we took advantage of data collected as part of an exercise intervention study that attempted to reduce the frequency of preeclampsia in women who had this condition in a prior pregnancy. We hypothesized that those women who self-reported long sleep duration across 24-hours in early pregnancy would have higher circulating concentrations of inflammatory cytokines, as well as a higher ratio of pro- to anti-inflammatory cytokines than women with regular sleep duration. We posited that a particularly relevant time to assess increased inflammatory response in conjunction with disturbed sleep would be 14-16 weeks gestation since this is the time when inappropriate inflammation might interfere with normal remodeling of the maternal arteries supplying the intervillous space $[42,43]$.

\section{MATERIALS AND METHODS}

\section{Participants}

This is a secondary analysis of data from a trial evaluating the efficacy of using moderate exercise as a prophylaxis in the prevention of recurrent preeclampsia $(\mathrm{N}=$ 140). Inclusion criteria included a history of preeclampsia without pre-existing diabetes, essential hypertension, or multiple gestations and no limitations of physical activity. Following collection of baseline health and questionnaire data, women were randomized into a moderate walking group or control group. The current sample consists of 85 women who had sleep and cytokine data at each time point. All women were enrolled in early gestation ( $15 \pm 2.8$ weeks $)$. Sleep and cytokine data were collected at 15, 25, and 35 weeks gestation. The Institutional Review Board at the University of Pittsburgh approved this study and all women signed informed consent.

\section{Sleep Variables}

Two sleep variables were identified. Sleep Satisfaction was determined through a single question that asked the degree to which a participant felt she got enough sleep (Never, Sometimes, Often or Routinely). Participants were dichotomized into NO (Never or Sometimes) or YES (Often or Routinely). Sleep Duration was assessed from a single question on the Paffenbarger exercise questionnaire [44]. Participants reported the number hours they spent sleeping or reclining each day (across a 24-hour period). Hence, these data likely include naps. The range was from 5-13 hours. We initially defined short sleep duration as less than 7 hours. However, there were few women $(n=4)$ with short sleep duration $(<7$ hours) so data were dichotomized based on the mean ( $8.8 \pm 1.4$ hours) and median ( 9 hours), into regular sleepers $(<9$ hours) and long sleepers $(\geq 9$ hours). The rationale was based on suggested practice recommendations for pregnant women [45] and that pregnant women generally report longer sleep duration, particularly when assessed over 24-hours [15, 45].

\section{Cytokine Assays}

The proinflammatory cytokines IL-2, -6, -8, IFN $\gamma$, GM$\mathrm{CSF}, \mathrm{TNF} \alpha$ and the anti-inflammatory cytokines IL-4, -5, and -10 were measured in duplicate by Luminex technology. Luminex Multiplex Bead Immunoassays (Biosource; Invitrogen, Carlsbad, CA) are solid phase sandwich immunoassays, which are analyzed with a Luminex $100^{\mathrm{TM}}$ instrument. These specific pro- and anti-inflammatory cytokines are in this standard kit. By monitoring the spectral properties of the beads and the amount of associated RPhycoerythrin (RPE) fluorescence, the concentration of one or more analytes can be determined. Samples were measured in duplicate. Inter-assay variation for each cytokine was as follows: IL-2 $=7.8 \%$, IL-6 $=4.4 \%$, IL-8 $=6.2 \%$, IFN $\gamma=$ $8.6 \%$, GM-CSF $=5.7 \%$, TNF $\alpha=7.4 \%$, IL-4 $=5.9 \%$, IL-5 = $7.1 \%$, IL-10 $=5.8 \%$.

\section{Data Management and Statistical Analysis}

Means and percentages of demographic and clinical variable values were determined for descriptive purposes. Participants were dichotomized into two groups based on median sleep duration by self-report across 24-hours at 15 weeks gestation: regular sleepers $(<9$ hours) and long sleepers ( $\geq 9$ hours). The distribution of each cytokine was assessed. None of the cytokine data were normally distributed so individual cytokine values were log transformed for normalization. The pro-inflammatory group consisted of IL2, IL6, IL8, IFN $\gamma$, TNF $\alpha$, and GM-CSF. The anti-inflammatory group consisted of IL4, IL5, and IL10. The pro- to anti-inflammatory ratio was calculated as the multiples of the median (MoMs) for each relevant cytokine type to normalize the data for comparison. This procedure allowed for standardization by creating comparable units as well as reducing the skewness that is apparent with cytokine data [46]. A repeated measures analysis of variance was performed using SAS Proc Mixed procedure to test for group, time and group*time interactions to examine whether long sleep duration in early pregnancy is related to changes in the means of individual cytokines and/or the ratio of proto anti-inflammatory cytokines across time. Models controlled for the covariates age, BMI, race, and treatment group (walking versus control). We used a more stringent $\mathrm{p}$ value $<.01$ for main effects due to multiple comparisons.

\section{RESULTS}

Table 1 describes the maternal characteristics of the entire cohort, as well as by groups: regular ( $<9$ hours) and 
Table 1. Maternal Characteristics at Enrollment for Entire Cohort of Women and for those who Slept $<$ or $\geq 9$ Hours (Mean ( SD or percent))

\begin{tabular}{|c|c|c|c|c|}
\hline & $\begin{array}{l}\text { Entire Cohort } \\
\qquad(\mathbf{N}=\mathbf{8 5})\end{array}$ & $\begin{array}{c}<9 \text { Hours } \\
(N=42)\end{array}$ & $\begin{array}{l}\geq 9 \text { Hours } \\
(N=43)\end{array}$ & $\begin{array}{c}\text { Test-Statistic (df) } \\
\text { p-value }\end{array}$ \\
\hline \multicolumn{5}{|c|}{ Demographics } \\
\hline Age & $30.1(4.9)$ & $30.2(4.5)$ & $30.0(5.4)$ & $\mathrm{t}(83)=0.22, \mathrm{p}=0.83$ \\
\hline$\%$ Caucasian & $\begin{array}{c}84.7 \\
(\mathrm{n}=72)\end{array}$ & $\begin{array}{c}88.1 \\
(\mathrm{n}=37)\end{array}$ & $\begin{array}{c}81.4 \\
(n=35)\end{array}$ & $\chi^{2}(1)=0.74, p=.39$ \\
\hline Gravid Status (range 1-6) & $2.7(1.1)$ & $2.7(1.1)$ & $2.7(1.1)$ & $\mathrm{t}(83)=-.23, \mathrm{p}=.82$ \\
\hline Parity (range 1-6) & $1.3(.74)$ & $1.2(.58)$ & $1.3(.87)$ & $\mathrm{t}(81)=-.40, \mathrm{p}=.67$ \\
\hline \multicolumn{5}{|c|}{ Maternal Anthropometry } \\
\hline BMI $\left(\mathrm{kg} / \mathrm{m}^{2}\right)$ at enrollment & $29.2(8.7)$ & $30.5(9.5)$ & $28.0(7.7)$ & $\mathrm{t}(83)=1.30, \mathrm{p}=0.20$ \\
\hline$\%$ Normal $(<25.0)$ & $\begin{array}{c}37.7 \\
(\mathrm{n}=32)\end{array}$ & $\begin{array}{c}35.7 \\
(\mathrm{n}=15)\end{array}$ & $\begin{array}{c}39.5 \\
(\mathrm{n}=17)\end{array}$ & $\chi^{2}(1)=0.13, p=.72$ \\
\hline \multicolumn{5}{|c|}{ Smoking Status } \\
\hline$\%$ Never & $\begin{array}{c}62.4 \\
(\mathrm{n}=53)\end{array}$ & $\begin{array}{c}57.1 \\
(\mathrm{n}=24)\end{array}$ & $\begin{array}{c}67.4 \\
(n=29)\end{array}$ & \multirow{3}{*}{ Fisher Exact $=.22$} \\
\hline$\%$ Quit & $\begin{array}{c}27.1 \\
(n=23)\end{array}$ & $\begin{array}{c}26.2 \\
(n=11)\end{array}$ & $\begin{array}{c}27.9 \\
(\mathrm{n}=12)\end{array}$ & \\
\hline$\%$ Current smoker & $\begin{array}{l}10.6 \\
(\mathrm{n}=9)\end{array}$ & $\begin{array}{l}16.7 \\
(\mathrm{n}=7)\end{array}$ & $\begin{array}{c}4.7 \\
(n=2)\end{array}$ & \\
\hline$\%$ Assigned to Walking Group & $\begin{array}{c}55.3 \\
(\mathrm{n}=47)\end{array}$ & $\begin{array}{c}57.1 \\
(\mathrm{n}=24)\end{array}$ & $\begin{array}{c}53.5 \\
(\mathrm{n}=23)\end{array}$ & \multirow{2}{*}{$\chi^{2}(1)=0.12, p=0.74$} \\
\hline$\%$ Assigned to Control Group & $\begin{array}{c}44.7 \\
(n=38)\end{array}$ & $\begin{array}{c}42.9 \\
(n=18)\end{array}$ & $\begin{array}{c}46.5 \\
(n=20)\end{array}$ & \\
\hline$\%$ Not Satisfied with Sleep & $\begin{array}{c}41.2 \\
(n=35)\end{array}$ & $\begin{array}{c}47.6 \\
(n=20)\end{array}$ & $\begin{array}{c}34.9 \\
(\mathrm{n}=15)\end{array}$ & $\chi^{2}(1)=1.42, p=0.23$ \\
\hline
\end{tabular}

long ( $\geq 9$ hours) sleepers. Participants were $30.1 \pm 4.9$ years, $84.7 \%$ Caucasian with a mean BMI $=29.2 \pm 8.7$ upon entry into the study. Nine $(10.6 \%)$ women reported smoking cigarettes at enrollment. Women who slept $\geq 9$ hours did not differ from those who slept $<9$ hours on any of the participant characteristics. In the complete cohort, approximately $41 \%(n=35)$ indicated they were not satisfied with their sleep at 15 weeks gestation. Fig. (1) shows the distribution of total sleep duration at 15 weeks. Sleep duration also changed across time (data not shown).

Table 2 shows the means and standard deviations for all the cytokines evaluated. IL-2 changed across time being significantly higher at $\mathrm{T} 1$ than at $\mathrm{T} 2$ or $\mathrm{T} 3(\mathrm{p}=.01)$ (Fig. 2). Other cytokines changed but did not meet the more stringent $\mathrm{p}$-value $<.01$. IL-6 differed by group $(\mathrm{p}=.003)$. It was greater in long sleepers ( $\geq 9$ hours) compared to women who were regular sleepers ( $<9$ hours) (Fig. 3). There were no significant interactions. Concerning the pro- to antiinflammatory ratio, there were no significant changes across time, group differences or a group by time interaction.

\section{DISCUSSION}

We examined the distribution of total sleep duration across a 24-hour period in sedentary pregnant women all of whom had a previous preeclamptic pregnancy. Among this sample of 85 pregnant women over half reported 9 or more hours of total sleep within a 24-hour period at 15 weeks gestation. This is consistent with the current literature [14, 15, 45]. However, sedentary women, especially obese and pregnant, are likely to have longer sleep duration than active lean pregnant women [47-49]. We found that women who reported longer sleep duration in early gestation had higher IL-6 concentrations across pregnancy compared to women with regular sleep duration. This is consistent with previous literature [16]. A time effect was also observed for IL-2. We did not, however, observe a time $\mathrm{X}$ group interaction. These results partially support our hypothesis that poor sleep may contribute to an exaggerated inflammatory response prior to 20 weeks gestation, which could initiate pathophysio logical changes, (i.e. cardiovascular) associated with disease 


\section{Total Sleep Duration at 15 Weeks}

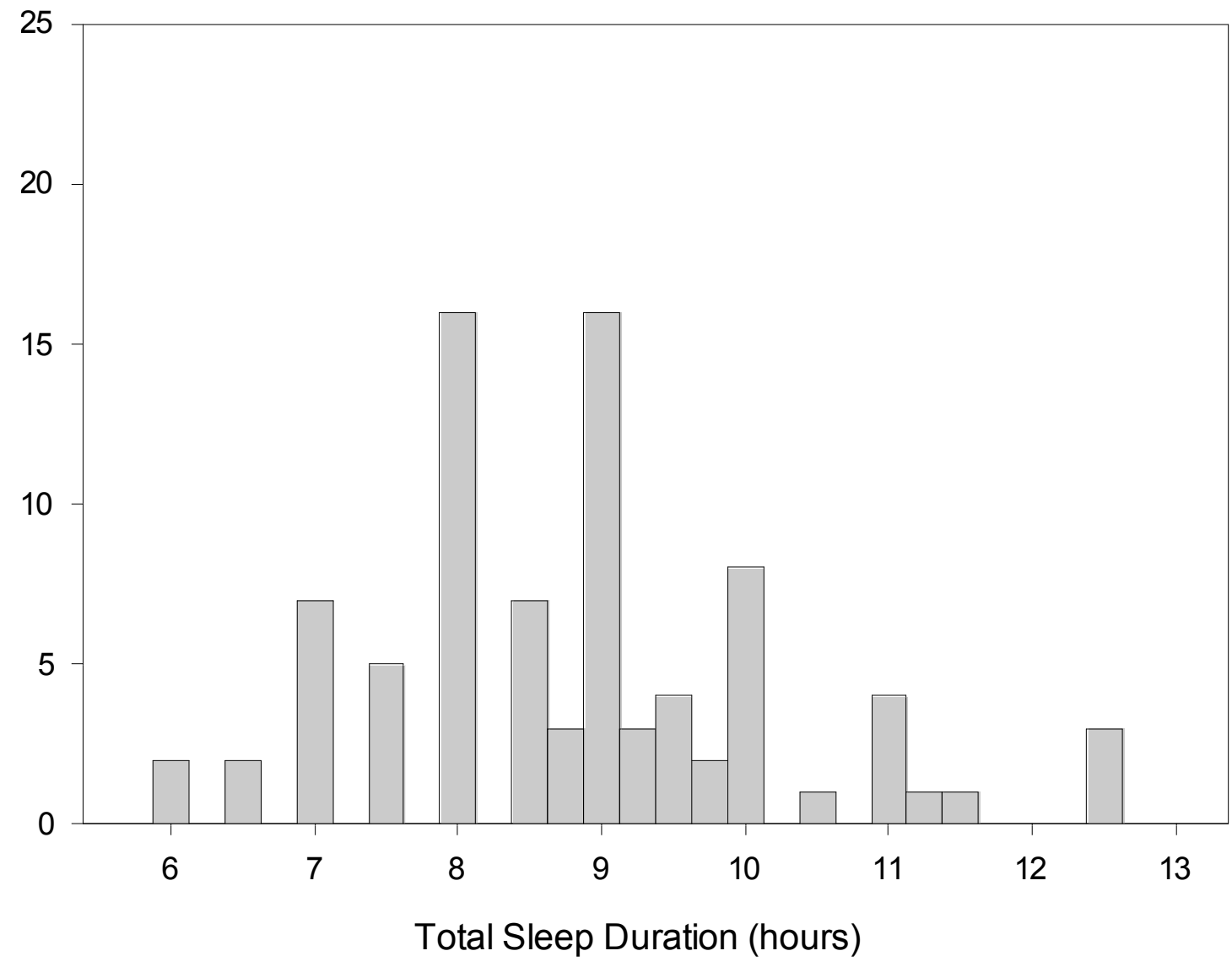

Fig. (1). Distribution of self-reported sleep duration at 15 weeks gestation.

Table 2. Cytokine Changes Over Time According to Group (Mean (STD))

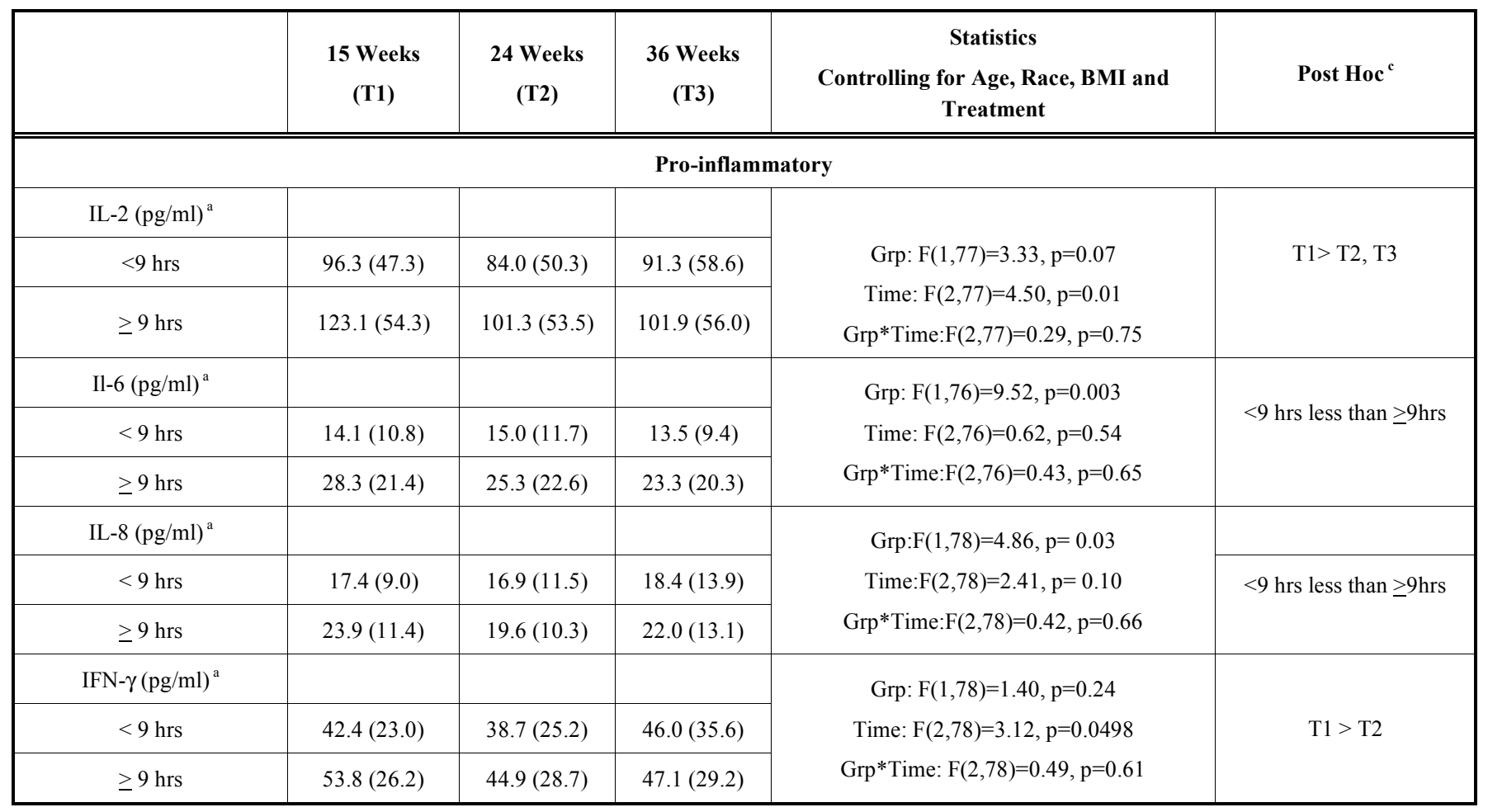




\begin{tabular}{|c|c|c|c|c|c|}
\hline $\mathrm{TNF}-\alpha(\mathrm{pg} / \mathrm{ml})^{\mathrm{a}}$ & & & & \multirow{3}{*}{$\begin{array}{c}\text { Grp: } \mathrm{F}(1,77)=0.23, \mathrm{p}=0.63 \\
\text { Time: } \mathrm{F}(2,77)=1.15, \mathrm{p}=0.32 \\
\text { Grp*Time: } \mathrm{F}(2,77)=0.01, \mathrm{p}=0.99\end{array}$} & \\
\hline$<9 \mathrm{hrs}$ & $30.7(17.4)$ & $29.0(21.0)$ & $33.0(28.5)$ & & \\
\hline$\geq 9 \mathrm{hrs}$ & $37.6(24.1)$ & $31.1(21.7)$ & $35.0(26.1)$ & & \\
\hline \multicolumn{4}{|l|}{ GM-CSF $(\mathrm{pg} / \mathrm{ml})^{\mathrm{a}}$} & \multirow{3}{*}{$\begin{array}{c}\text { Grp: } \mathrm{F}(1,76)=1.57, \mathrm{p}=0.22 \\
\text { Time: } \mathrm{F}(2,76)=0.91, \mathrm{p}=0.41 \\
\text { Grp*Time: } \mathrm{F}(2,76)=0.12, \mathrm{p}=0.88\end{array}$} & \\
\hline$<9 \mathrm{hrs}$ & $74.5(54.8)$ & $71.0(56.3)$ & $69.2(80.7)$ & & \\
\hline$\geq 9 \mathrm{hrs}$ & $107.6(118.0)$ & $73.9(47.8)$ & $87.4(76.9)$ & & \\
\hline \multicolumn{4}{|l|}{ Anti-inflammatory } & \multirow{4}{*}{$\begin{array}{c}\text { Grp: } \mathrm{F}(1,78)=3.99, \mathrm{p}=0.049 \\
\text { Time: } \mathrm{F}(2,78)=3.54, \mathrm{p}=0.034 \\
\text { Grp*Time: } \mathrm{F}(2,78)=0.46, \mathrm{p}=0.63\end{array}$} & \multirow{4}{*}{$\begin{array}{c}<9 \text { hrs less than } \geq 9 \mathrm{hrs} \\
\mathrm{T} 1>\mathrm{T} 2, \mathrm{~T} 3\end{array}$} \\
\hline \multicolumn{4}{|l|}{$\mathrm{IL}-4(\mathrm{pg} / \mathrm{ml})^{\mathrm{a}}$} & & \\
\hline$<9 \mathrm{hrs}$ & $63.8(47.4)$ & $60.3(45.4)$ & $53.3(42.1)$ & & \\
\hline$\geq 9 \mathrm{hrs}$ & $79.9(45.8)$ & $65.1(39.2)$ & $69.9(49.3)$ & & \\
\hline $\mathrm{IL}-5(\mathrm{pg} / \mathrm{ml})^{\mathrm{a}}$ & & & & \multirow{3}{*}{$\begin{array}{c}\text { Grp: } F(1,77)=2.17, p=0.15 \\
\text { Time: } F(2,77)=0.72, p=0.49 \\
\text { Grp*Time: } F(2,77)=0.10,0.90\end{array}$} & \\
\hline$<9 \mathrm{hrs}$ & $6.9(4.1)$ & $6.9(5.6)$ & $8.0(7.0)$ & & \\
\hline$\geq 9 \mathrm{hrs}$ & $8.7(4.8)$ & $8.5(6.2)$ & $8.2(5.2)$ & & \\
\hline \multicolumn{4}{|l|}{$\mathrm{IL}-10(\mathrm{pg} / \mathrm{ml})^{\mathrm{a}}$} & \multirow{3}{*}{$\begin{array}{c}\text { Grp: } \mathrm{F}(1,76)=3.27, \mathrm{p}=0.07 \\
\text { Time: } \mathrm{F}(2,76)=0.13, \mathrm{p}=0.88 \\
\text { Grp*Time: } \mathrm{F}(2,76)=0.27, \mathrm{p}=0.76\end{array}$} & \\
\hline$<9 \mathrm{hrs}$ & $12.6(9.1)$ & $12.9(9.0)$ & $14.2(16.7)$ & & \\
\hline$\geq 9 \mathrm{hrs}$ & $17.9(14.2)$ & $15.7(10.7)$ & $18.0(15.1)$ & & \\
\hline $\begin{array}{l}\text { Ratio Pro:Anti- } \\
\text { inflammatory } \text { MoM }^{\mathrm{b}}\end{array}$ & & & & \multirow{3}{*}{$\begin{array}{c}\text { Grp: } \mathrm{F}(1,78)=0.45, \mathrm{p}=0.50 \\
\text { Time: } \mathrm{F}(2,78)=4.34, \mathrm{p}=0.02 \\
\text { Grp*Time: } \mathrm{F}(2,78)=0.80, \mathrm{p}=0.45\end{array}$} & \multirow{3}{*}{$\mathrm{T} 2>\mathrm{T} 3$} \\
\hline$<9 \mathrm{hrs}$ & $1.0(0.2)$ & $1.1(0.4)$ & $1.0(0.2)$ & & \\
\hline$\geq 9 \mathrm{hrs}$ & $1.1(0.6)$ & $1.2(0.4)$ & $1.1(0.3)$ & & \\
\hline
\end{tabular}

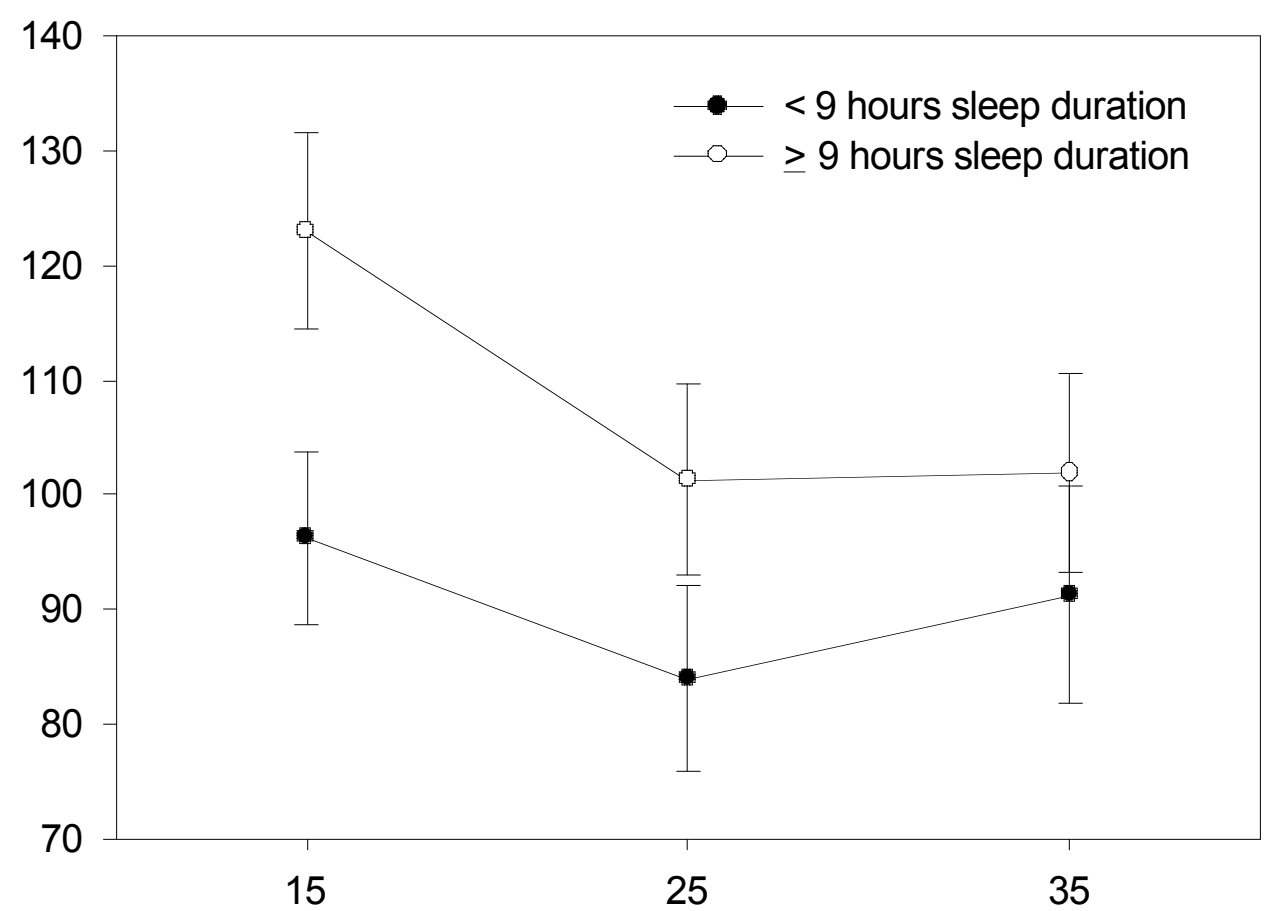

Gestational Week

Fig. (2). Concentrations of IL-2 (pg/ml) assayed at 15, 25 and 36 weeks gestation. Women who self-reported $\geq 9$ hours of sleep per night (Open circles) had higher concentrations $(\mathrm{p}<.07)$ across pregnancy compared to women who self-reported $<9$ hours of sleep per night (closed circles). IL-2 values significantly dropped across pregnancy $(\mathrm{p}<.01)$. Of note: Luminex was used to assay a series of cytokines. Hence, by nature of the assay the concentrations are significantly higher compared to ELISA kits [86]. 


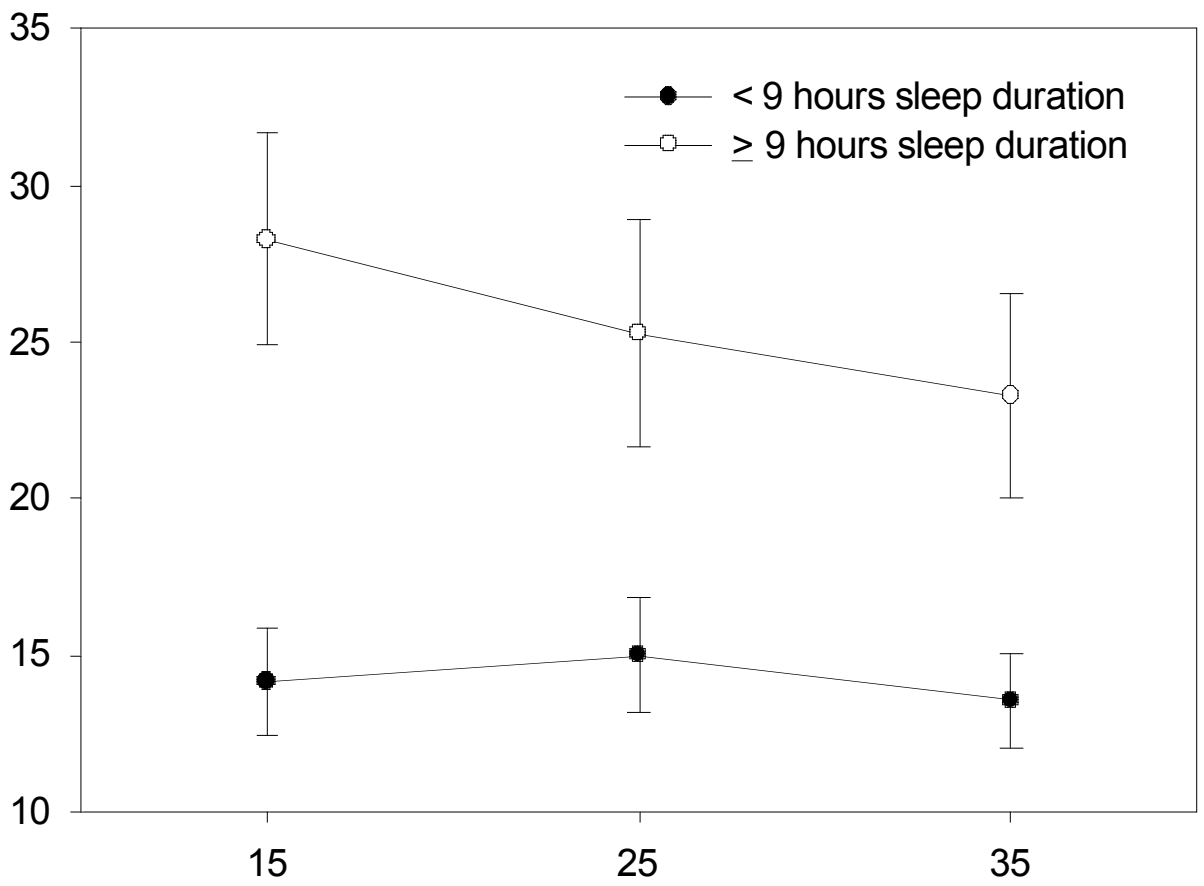

\section{Gestational Week}

Fig. (3). Concentrations of IL-6 (pg/ml) assayed at 15, 25 and 36 weeks gestation. Women who self-reported $\geq 9$ hours of sleep per night (Open circles) had higher concentrations $(\mathrm{p}=.003)$ across pregnancy compared to women who self-reported $<9$ hours of sleep per night (closed circles). However, there was no significant change across time. Of note: Luminex was used to assay a series of cytokines. Hence, by nature of the assay, which still remain unclear, the concentrations are significantly higher compared to values obtained via ELISA [86].

development and future morbidity [50]. While long sleep duration has not historically been considered poor sleep, emerging evidence is shifting this paradigm [3, 10, 11]. Understanding the role of sleep is critical not only to pregnancy outcomes, but for future health conditions as well. Women who have had a preeclamptic pregnancy are at increased risk for future cardiovascular disease [51-53]. This risk is evidenced by increased blood pressure readings, inflammation, impaired endothelial function and dyslipidemia long after delivery [54-57]. These maternal complications can also have extensive negative consequences for the offspring who are also at increased risk for adolescent and adult onset cardiovascular disease, metabolic syndrome and diabetes [58, 59]. Further exploration of these preliminary findings is needed to facilitate interpretation as well as gauge the value of assessing pregnancy-related sleep disturbance as a potential risk factor in the development of adverse outcomes.

The effects of long sleep duration during pregnancy are not clear despite several reports, including our current data, suggesting that a large percentage of pregnant women report long sleep ( $\geq 9$ hours). An in-depth exploration of this relationship may have significant clinical relevance for pregnancy since long sleep duration is a recognized independent predictor of hypertension [26, 60-62], a hallmark sign of preeclampsia [54, 63]. We hypothesize that the inflammatory pathway may connect long sleep duration and high blood pressure. Recent lines of data support this hypothesis. Williams et al. show an association between long sleep duration and elevated mean third-trimester blood pressures and preeclampsia risk in pregnant women [26]. We show that long sleep duration is associated with increased inflammation and the extant literature supports an association between increased inflammation and pregnancyinduced hypertension/ preeclampsia [37, 64-68]. Moreover, preeclampsia is proposed to be an endothelial cell disorder $[53,54,69]$ in which cytokines are both potent stimulators and products of endothelial cells $[70,71]$. Although provocative, additional studies are required to examine sleep, inflammation and outcome concomitantly in order to confirm these relationships.

The relationship between long sleep and adverse health outcomes is likely mediated by an array of correlates. Long sleepers report more depressive symptoms, they exercise less, are more often obese, they are often not married, and they are of lower socioeconomic status [8]. Unfortunately, these variables were unavailable from this cohort. We recognize this as a limitation. Relevant to the hypotheses evaluated here is that each of these correlates contribute to increased inflammation [72]. Interestingly Patel and colleagues report that other pregnancy-related sleep disorders, such as restless legs syndrome and sleep disordered breathing, also predispose to long sleep duration [10] which may compound the exaggerated inflammatory response to long sleep. Presently, it is unclear as to whether long sleep duration in pregnancy is solely an independent factor or a mediator of other established risk factors as well.

Many correlates have a bi-directional relationship with sleep. For instance, long sleep duration has been shown to predict increased weight/obesity, while increased weight/obesity has been shown to predict longer sleep duration [8]. Our cohort of women was all overweight/obese 
and sedentary, and considered at high-risk for preeclampsia. This factor may also contribute to a percentage of women requiring longer sleep. Understanding the dynamics of this relationship is important since increased weight is highly correlated with increased systemic inflammation $[10,11]$ and preeclampsia [73, 74]. The increased levels of IL-6 are not surprising in this sample given the well established evidence that adipose tissue is a major source for IL-6 [75] and subsequent increased inflammation. However, the fact that recent evidence further demonstrates a U-shaped relationship with maternal serum IL-2 concentrations and BMI [76], as well as an increase in BMI with specific polymorphisms of the IL-4 receptor [77] suggests that sleep duration may be an additive factor in a complicated relationship. A clearer understanding is particularly important if we are to reduce the 50,000 pregnancies afflicted yearly by pregnancy-related hypertension and preeclampsia $[57,63,78]$.

Although the study design was prospective, there are certain limitations to the interpretability of these findings. The primary study was not designed to evaluate the relationship between sleep and inflammatory markers. Thus, the sleep information used is a crude approximation of actual sleep habits. Despite this, our measure is similar and confirmatory of other studies of long sleep duration in women $[10,13,26]$. It does imply that more detailed sleep information is needed to fully elucidate these relationships. Specifically, the presence of snoring or sleep disordered breathing or restless legs syndrome was not ascertained in the study. It is well established that obesity is a risk factor for snoring and sleep disordered breathing [79] and inflammation $[76,80]$; both of which increase the risk of adverse pregnancy outcomes [22, 24, 25]. Other psychosocial correlates, including depression and stress were also not considered. These are recognized to contribute to inflammation and adverse pregnancy outcomes [81-83]. Hence, it is likely that IL-6 may have been elevated prior to enrollment into the study. Future studies need to take these correlates into consideration. Although the assessment of nocturnal and daytime sleep is a limitation, the data are also unique. Sleep duration across 24-hours is likely to include daytime napping which is noted to be higher in pregnant women [15]. We note the small sample size is probably too small to have sufficient power, but the confidence in these preliminary findings is augmented with multiple assessments from each participant in a cohort of high-risk women. While a strength, the homogeneity of only testing women with history of preeclampsia restricts the generalizability of our findings. Furthermore, data on the interval between pregnancies was not collected. Hence, we are unable to determine when the sleep duration changed (if at all). A more heterogeneous and larger cohort is needed in order to understand these relationships better and to more accurately identify which women are most at risk. Finally, we are cognizant that the unavailability of delivery and outcome data, currently blinded as part of the primary study, precludes an evaluation of sleep, inflammation and outcome.

We had hoped that the ratio of an array of proinflammatory to anti-inflammatory markers would be a better indicator of an "inflammatory" phenotype than a single cytokine such as IL-6. However, there are limitations even though the approach we chose (for which we did not find differences) would seem a more sensitive approach to defining inflammation [84]. Using the MoMs allowed us to combine different cytokines present at different concentrations. However, not all cytokines are equipotent in their activities. It is unclear whether there are clinically relevant distinctions when the median of a proinflammatory cytokine such as IL-6 is compared to the median of an antiinflammatory cytokine such as IL-10.

In summary, we suggest that long sleep duration early in gestation is associated with an increase in basal inflammation. This inflammation underlies a defective placentation characterized by reduced invasion of fetal extravillious trophoblast cells and reduced remodeling of maternal uteroplacental spiral arteries which initializes subsequent pathophysiology [37]. Despite the preliminary nature of these relationships, we hypothesize that in conjunction with other factors, including a history of preeclampsia/preterm birth, obesity and a sedentary lifestyle $[66,74,85]$, the $25-40 \%$ of pregnant women with significant sleep disturbances during the first trimester may be at further increased risk for adverse outcomes. The extent to which an exaggerated inflammatory response is the biological mediating pathway requires further evaluation.

\section{CONFLICT OF INTEREST}

The authors confirm that this article content has no conflicts of interest.

\section{ACKNOWLEDGEMENTS}

Supported by funding from NIH R01 NR05275, R00 NR010813, and P01 HD030367 Dr. Okun's time is supported by R00 NR010813.

\section{REFERENCES}

[1] Gangwisch JE, Heymsfield SB, Boden-Albala B, et al. Short sleep duration as a risk factor for hypertension: analyses of the first National Health and Nutrition Examination Survey. Hypertension 2006; 47(5): 833-9.

[2] Meisinger C, Heier M, Lowel H, Schneider A, Doring A. Sleep duration and sleep complaints and risk of myocardial infarction in middle-aged men and women from the general population: the MONICA/KORA Augsburg cohort study. Sleep 2007; 30(9): 11217.

[3] Gangwisch JE, Heymsfield SB, Boden-Albala B, et al. Sleep duration as a risk factor for diabetes incidence in a large U.S. sample. Sleep 2007; 30(12): 1667-73.

[4] Cappuccio FP, Stranges S, Kandala NB, et al. Gender-specific associations of short sleep duration with prevalent and incident hypertension: the Whitehall II Study. Hypertension 2007; 50(4): 693-700.

[5] Facco FL, Grobman WA, Kramer J, Ho KH, Zee PC. Self-reported short sleep duration and frequent snoring in pregnancy: impact on glucose metabolism. Am J Obstet Gynecol 2010; 203(2): 142-5.

[6] Vgontzas AN, Lin HM, Papaliaga M, et al. Short sleep duration and obesity: the role of emotional stress and sleep disturbances. Int J Obes (Lond) 2008; 32(5): 801-9.

[7] National Sleep Foundation. Summary of Findings of the 2007 Sleep in America Poll, USA: NSP 2007.

[8] Grandner MA, Drummond SP. Who are the long sleepers? Towards an understanding of the mortality relationship. Sleep Med Rev 2007; 11(5): 341-60.

[9] Magee CA, Iverson DC, Caputi P. Factors associated with short and long sleep. Prev Med 2009; 49(6): 461-7.

[10] Patel SR, Malhotra A, Gottlieb DJ, White DP, Hu FB. Correlates of long sleep duration. Sleep 2006; 29(7): 881-9. 
[11] Hall MH, Muldoon MF, Jennings JR, Buysse DJ, Flory JD, Manuck SB. Self-reported sleep duration is associated with the metabolic syndrome in midlife adults. Sleep 2008; 31(5): 635-43.

[12] Yaggi HK, Araujo AB, McKinlay JB. Sleep duration as a risk factor for the development of type 2 diabetes. Diabetes Care 2006; 29(3): 657-61.

[13] Heslop P, Smith GD, Metcalfe C, Macleod J, Hart C. Sleep duration and mortality: The effect of short or long sleep duration on cardiovascular and all-cause mortality in working men and women. Sleep Med 2002; 3(4): 305-14.

[14] Facco FL, Kramer J, Ho KH, Zee PC, Grobman WA. Sleep disturbances in pregnancy. Obstet Gynecol 2010; 115(1): 77-83.

[15] Lee KA. Sleep during pregnancy and postpartum. In: Lee-Chiong T, Ed. Encyclopedia of Sleep Medicine. NJ: John Wiley \& Sons Inc 2006; pp. 629-35.

[16] Okun ML, Coussons-Read ME. Sleep disruption during pregnancy: how does it influence serum cytokines? J Reprod Immunol 2007; 73(2): 158-65.

[17] Pien GW, Schwab RJ. Sleep disorders during pregnancy. Sleep 2004; 27(7): 1405-17.

[18] Santiago JR, Nolledo MS, Kinzler W, Santiago TV. Sleep and sleep disorders in pregnancy. Ann Intern Med 2001; 134(5): 396408.

[19] Bourjeily G, Ankner G, Mohsenin V. Sleep-disordered breathing in pregnancy. Clin Chest Med 2011; 32(1): 175-89.

[20] Champagne KA, Kimoff RJ, Barriga PC, Schwartzman K. Sleep disordered breathing in women of childbearing age and during pregnancy. Indian J Med Res 2010; 131: 285-301.

[21] Edwards N, Sullivan CE. Sleep-Disordered Breathing in Pregnancy. Sleep Med Clin 2008; 3: 81-95.

[22] Bourjeily G, Raker CA, Chalhoub M, Miller MA. Pregnancy and fetal outcomes of symptoms of sleep-disordered breathing. Eur Respir J 2010; 36(4): 849-55.

[23] Reid J, Skomro R, Cotton D et al. Pregnant women with gestational hypertension may have a high frequency of sleep disordered breathing. Sleep 2011; 34(8): 1033-8.

[24] Tauman R, Many A, Deutsch V, et al. Maternal snoring during pregnancy is associated with enhanced fetal erythropoiesis--a preliminary study. Sleep Med 2011; 12(5): 518-22.

[25] Yinon D, Lowenstein L, Suraya S, et al. Pre-eclampsia is associated with sleep-disordered breathing and endothelial dysfunction. Eur Respir J 2006; 27(2): 328-33.

[26] Williams MA, Miller RS, Qiu C, Cripe SM, Gelaye B, Enquobahrie D. Associations of early pregnancy sleep duration with trimester-specific blood pressures and hypertensive disorders in pregnancy. Sleep 2010; 33(10): 1363-71.

[27] Qiu C, Enquobahrie D, Frederick IO, Abetew D, Williams MA. Glucose intolerance and gestational diabetes risk in relation to sleep duration and snoring during pregnancy: a pilot study. BMC Womens Health 2010; 10: 17.

[28] Roberts JM. Pregnancy-Related hypertension. In: Creasey RK, Resnik R, Eds. Maternal-Fetal Medicine. $5^{\text {th }}$ Ed. Philadelphia: Saunders 2004; pp. 859-99.

[29] Solomon CG, Seely EW. Hypertension in pregnancy. Endocrinol Metab Clin North Am 2006; 35(1): 157-71.

[30] Bautista LE. Inflammation, endothelial dysfunction, and the risk of high blood pressure: epidemiologic and biological evidence. J Hum Hypertens 2003; 17(4): 223-30.

[31] Conrad KP, Miles TM, Benyo DF. Circulating levels of immunoreactive cytokines in women with preeclampsia. Am J Reprod Immunol 1998; 40(2): 102-11.

[32] Challis JR, Lockwood CJ, Myatt L, Norman JE, Strauss JF, III, Petraglia F. Inflammation and pregnancy. Reprod Sci 2009; 16(2): 206-15.

[33] Simhan HN, Krohn MA. First-trimester cervical inflammatory milieu and subsequent early preterm birth. Am J Obstet Gynecol 2009; 200(4): 377-4.

[34] Simhan HN, Bodnar LM, Kim KH. Lower genital tract inflammatory milieu and the risk of subsequent preterm birth: an exploratory factor analysis. Paediatr Perinat Epidemiol 2011; 25(3): 277-82.

[35] Bachour A, Teramo K, Hiilesmaa V, Maasilta P. Increased plasma levels of inflammatory markers and upper airway resistance during sleep in pre-eclampsia. Sleep Med 2008; 9(6): 667-74.
[36] Okun ML, Hall M, Coussons-Read ME. Sleep disturbances increase interleukin-6 production during pregnancy: implications for pregnancy complications. Reprod Sci 2007; 14(6): 560-7.

[37] Redman CW, Sargent IL. Immunology of pre-eclampsia. Am J Reprod Immunol 2010; 63(6): 534-43.

[38] Sacks GP, Studena K, Sargent K, Redman CW. Normal pregnancy and preeclampsia both produce inflammatory changes in peripheral blood leukocytes akin to those of sepsis. Am J Obstet Gynecol 1998; 179(1): 80-6.

[39] Sargent IL, Borzychowski AM, Redman CW. NK cells and human pregnancy--an inflammatory view. Trends Immunol 2006; 27(9): 399-404.

[40] Azizieh F, Raghupathy R, Makhseed M. Maternal cytokine production patterns in women with pre-eclampsia. Am J Reprod Immunol 2005; 54(1): 30-7.

[41] Schipper EJ, Bolte AC, Schalkwijk CG, Van Geijn HP, Dekker GA. TNF-receptor levels in preeclampsia--results of a longitudinal study in high-risk women. J Matern Fetal Neonatal Med 2005; 18(5): 283-7.

[42] Bowen JM, Chamley L, Keelan JA, Mitchell MD. Cytokines of the placenta and extra-placental membranes: roles and regulation during human pregnancy and parturition. Placenta 2002; 23(4): 257-73.

[43] Roberts JM. Endothelial dysfunction in preeclampsia. Semin Reprod Endocrinol 1998; 16(1): 5-15.

[44] Paffenbarger RS, Jr., Blair SN, Lee IM, Hyde RT. Measurement of physical activity to assess health effects in free-living populations. Med Sci Sports Exerc 1993; 25(1): 60-70.

[45] Wolfson AR, Lee KA. Pregnancy and the Post Partum. In: Kryger MH, Roth T, Dement WC, Eds. Principles and Practices of Sleep Medicine. $4^{\text {th }}$ ed. Philadelphia: Elsevier Saunders 2005; pp. 127886.

[46] Bishop JC, Dunstan FD, Nix BJ, Reynolds TM, Swift A. All MoMs are not equal: some statistical properties associated with reporting results in the form of multiples of the median. Am J Hum Genet 1993; 52(2): 425-30.

[47] Althuizen E, van Poppel MN, de Vries JH, Seidell JC, van MW. Postpartum behaviour as predictor of weight change from before pregnancy to one year postpartum. BMC Public Health 2011; 11: 165.

[48] Cheek RE, Shaver JL, Lentz MJ. Lifestyle practices and nocturnal sleep in midlife women with and without insomnia. Biol Res Nurs 2004; 6(1): 46-58.

[49] de Castro Toledo Guimaraes LH, de Carvalho LB, Yanaguibashi G, do Prado GF. Physically active elderly women sleep more and better than sedentary women. Sleep Med 2008; 9(5): 488-93.

[50] Okun ML, Coussons-Read M, Hall M. Disturbed sleep is associated with increased C-reactive protein in young women. Brain Behav Immun 2009; 23(3): 351-4.

[51] Roberts JM, Gammill H. Pre-eclampsia and cardiovascular disease in later life. Lancet 2005; 366(9490): 961-2.

[52] Roberts JM, Hubel CA. Pregnancy: a screening test for later life cardiovascular disease. Womens Health Issues 2010; 20(5): 304-7.

[53] Wolf M, Hubel CA, Lam C, et al. Preeclampsia and future cardiovascular disease: potential role of altered angiogenesis and insulin resistance. J Clin Endocrinol Metab 2004; 89(12): 6239-43.

[54] Agatisa PK, Ness RB, Roberts JM, Costantino JP, Kuller LH, McLaughlin MK. Impairment of endothelial function in women with a history of preeclampsia: an indicator of cardiovascular risk. Am J Physiol Heart Circ Physiol 2004; 286(4): H1389-93.

[55] Manten GT, Sikkema MJ, Voorbij HA, Visser GH, Bruinse HW, Franx A. Risk factors for cardiovascular disease in women with a history of pregnancy complicated by preeclampsia or intrauterine growth restriction. Hypertens Pregnancy 2007; 26(1): 39-50.

[56] Melchiorre K, Sutherland GR, Baltabaeva A, Liberati M, Thilaganathan B. Maternal cardiac dysfunction and remodeling in women with preeclampsia at term. Hypertension 2011; 57(1): 8593.

[57] Staff AC, Dechend R, Pijnenborg R. Learning from the placenta: acute atherosis and vascular remodeling in preeclampsia-novel aspects for atherosclerosis and future cardiovascular health. Hypertension 2010; 56(6): 1026-34.

[58] Tenhola S, Rahiala E, Martikainen A, Halonen P, Voutilainen R. Blood pressure, serum lipids, fasting insulin, and adrenal hormones in 12-year-old children born with maternal preeclampsia. J Clin Endocrinol Metab 2003; 88(3): 1217-22. 
[59] Vatten LJ, Romundstad PR, Holmen TL, Hsieh CC, Trichopoulos $\mathrm{D}$, Stuver SO. Intrauterine exposure to preeclampsia and adolescent blood pressure, body size, and age at menarche in female offspring. Obstet Gynecol 2003; 101(3): 529-33.

[60] Alvarez GG, Ayas NT. The impact of daily sleep duration on health: a review of the literature. Prog Cardiovasc Nurs 2004; 19(2): 56-9.

[61] Bjorvatn B, Sagen IM, Oyane N, et al. The association between sleep duration, body mass index and metabolic measures in the Hordaland Health Study. J Sleep Res 2007; 16(1): 66-76.

[62] Gottlieb DJ, Redline S, Nieto FJ, et al. Association of usual sleep duration with hypertension: the Sleep Heart Health Study. Sleep 2006; 29(8): 1009-14.

[63] Roberts JM, Gammill HS. Preeclampsia: recent insights. Hypertension 2005; 46(6): 1243-9.

[64] Amory JH, Hitti J, Lawler R, Eschenbach DA. Increased tumor necrosis factor-alpha production after lipopolysaccharide stimulation of whole blood in patients with previous preterm delivery complicated by intra-amniotic infection or inflammation. Am J Obstet Gynecol 2001; 185(5): 1064-7.

[65] El Shazly S, Makhseed M, Azizieh F, Raghupathy R. Increased expression of pro-inflammatory cytokines in placentas of women undergoing spontaneous preterm delivery or premature rupture of membranes. Am J Reprod Immunol 2004; 52(1): 45-52.

[66] Freeman DJ, McManus F, Brown EA, et al. Short- and long-term changes in plasma inflammatory markers associated with preeclampsia. Hypertension 2004; 44(5): 708-14.

[67] Garcia RG, Celedon J, Sierra-Laguado J, et al. Raised C-reactive protein and impaired flow-mediated vasodilation precede the development of preeclampsia. Am J Hypertens 2007; 20(1): 98103.

[68] Velez DR, Fortunato SJ, Morgan N, et al. Patterns of cytokine profiles differ with pregnancy outcome and ethnicity. Hum Reprod 2008; 23(8): 1902-9.

[69] Roberts JM, Taylor RN, Musci TJ, Rodgers GM, Hubel CA, McLaughlin MK. Preeclampsia: an endothelial cell disorder. Am J Obstet Gynecol 1989; 161(5): 1200-4.

[70] Chen LM, Liu B, Zhao HB, Stone P, Chen Q, Chamley L. IL-6, TNFalpha and TGFbeta promote nonapoptotic trophoblast deportation and subsequently causes endothelial cell activation. Placenta 2010; 31(1): 75-80.

[71] Walsh SW. Plasma from preeclamptic women stimulates transendothelial migration of neutrophils. Reprod Sci 2009; 16(3): $320-5$.

[72] O'connor MF, Bower JE, Cho HJ, et al. To assess, to control, to exclude: effects of biobehavioral factors on circulating inflammatory markers. Brain Behav Immun 2009; 23(7): 887-97.
[73] Fialova L, Kalousova M, Soukupova J, et al. Markers of inflammation in preeclampsia. Prague Med Rep 2004; 105(3): 30110.

[74] Schiessl B. Inflammatory response in preeclampsia. Mol Aspects Med 2007; 28(2): 210-9.

[75] Park HS, Park JY, Yu R. Relationship of obesity and visceral adiposity with serum concentrations of CRP, TNF-alpha and IL-6. Diabetes Res Clin Pract 2005; 69(1): 29-35.

[76] Madan JC, Davis JM, Craig WY, et al. Maternal obesity and markers of inflammation in pregnancy. Cytokine 2009; 47(1): 61-4.

[77] Ha E, Yang SH, Yoo KI, et al. Interleukin 4 receptor is associated with an increase in body mass index in Koreans. Life Sci 2008; 82(19-20): 1040-3.

[78] Bodnar LM, Catov JM, Klebanoff MA, Ness RB, Roberts JM. Prepregnancy body mass index and the occurrence of severe hypertensive disorders of pregnancy. Epidemiology 2007; 18(2): 234-9.

[79] Maasilta P, Bachour A, Teramo K, Polo O, Laitinen LA. Sleeprelated disordered breathing during pregnancy in obese women. Chest 2001; 120(5): 1448-54.

[80] Ramsay JE, Ferrell WR, Crawford L, Wallace AM, Greer IA, Sattar N. Maternal obesity is associated with dysregulation of metabolic, vascular, and inflammatory pathways. J Clin Endocrinol Metab 2002; 87(9): 4231-7.

[81] Alder J, Fink N, Bitzer J, Hosli I, Holzgreve W. Depression and anxiety during pregnancy: a risk factor for obstetric, fetal and neonatal outcome? A critical review of the literature. J Matern Fetal Neonatal Med 2007; 20(3): 189-209.

[82] Brummelte S, Galea LA. Depression during pregnancy and postpartum: Contribution of stress and ovarian hormones. Prog Neuropsychopharmacol Biol Psychiatry 2010; 34(5): 766-76.

[83] Christian LM, Franco A, Iams JD, Sheridan J, Glaser R. Depressive symptoms predict exaggerated inflammatory responses to an in vivo immune challenge among pregnant women. Brain Behav Immun 2010; 24(1): 49-53.

[84] Breen EC, Reynolds SM, Cox C, et al. Multisite comparison of high-sensitivity multiplex cytokine assays. Clin Vaccine Immunol 2011; 18(8): 1229-42.

[85] Nohr EA, Timpson NJ, Andersen CS, Davey SG, Olsen J, Sorensen TI. Severe obesity in young women and reproductive health: the Danish National Birth Cohort. PLoS ONE 2009; 4(12): e8444.

[86] Breen EC, Reynolds SM, Cox C, et al. Multisite comparison of high-sensitivity multiplex cytokine assays. Clin Vaccine Immunol 2011; 18(8): 1229-42. 